\title{
Arterial changes in infants of smoking mothers
}

\author{
INGER ASMUSSEN \\ M.D. \\ Department of Obstretics and Gynaecology YA, Rigshospitalet, University of Copenhagen, \\ 2100 Copenhagen Ø, Denmark
}

\begin{abstract}
Summary
Examination of umbilical arteries and veins, and vessels in placental villi was carried out by electronmicroscopy in smoking and non-smoking mothers. Severe vascular changes were found in the smoking group. These findings suggest that similar changes may be present in the vessels of the newborn child. Stopping pregnant women from smoking may help to prevent CHD in their children in later life.
\end{abstract}

INTERVENTION and prophylaxis against ischaemic heart disease seems of little importance when symptoms are already present. Prevention should $\stackrel{\vec{\omega}}{\sigma}$ therefore be started in childhood before the supposed initial damage to the vessels and heart has begun. 3 . Recent studies, however, indicate that as far as or smoking is concerned the vessels might already be damaged at birth and that prevention should be $\mathcal{O}^{\circ}$ started during fetal life.

In the present study, ultrastructural examination $\bigcirc$ of biopsies from the umbilical artery (Asmussen and $\frac{9}{7}$ Kjeldsen, 1975), umbilical vein (Asmussen, 1977b) and vessels in the placental villi (Asmussen, 1977a) was carried out in a group of thirteen heavy smokers.

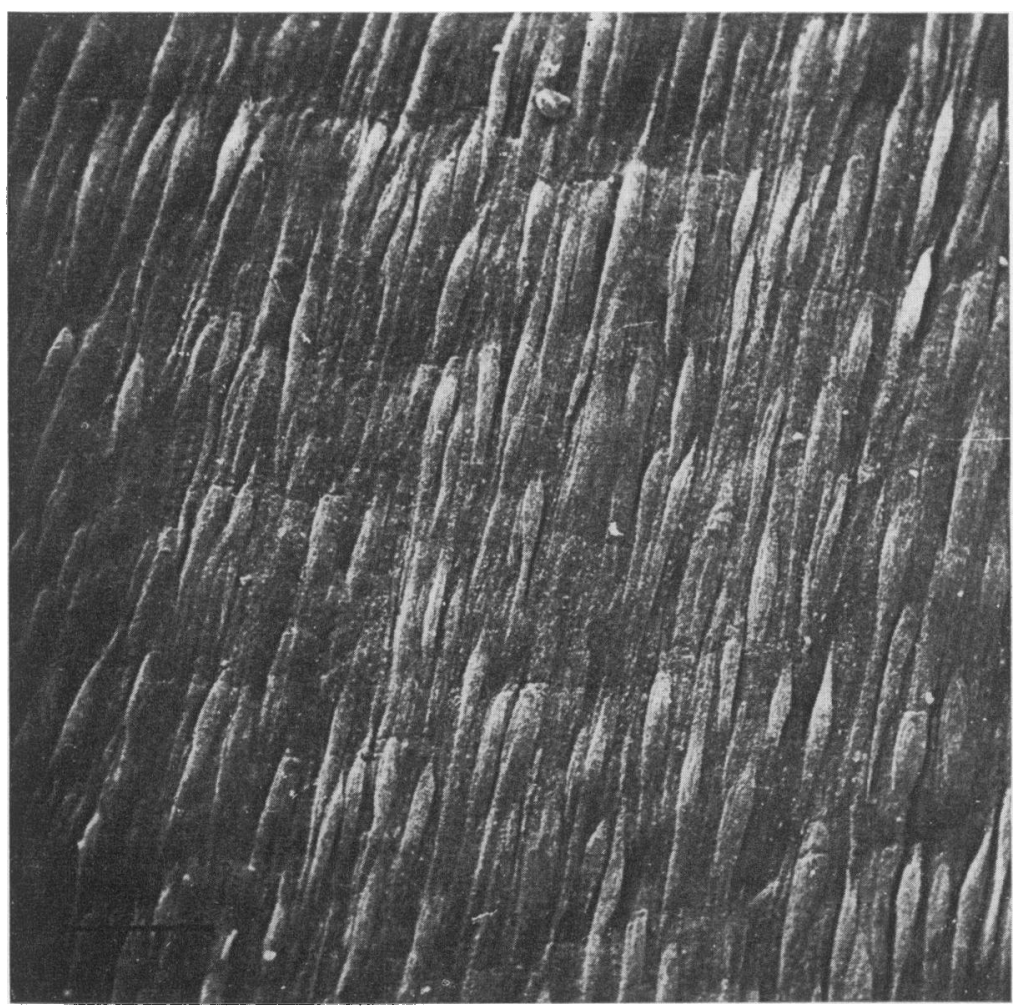

FIg. 1. Scanning electronmicrograph of an umbilical artery from a child of a non-smoking mother. Bar indicates $40 \mu \mathrm{m}$. 


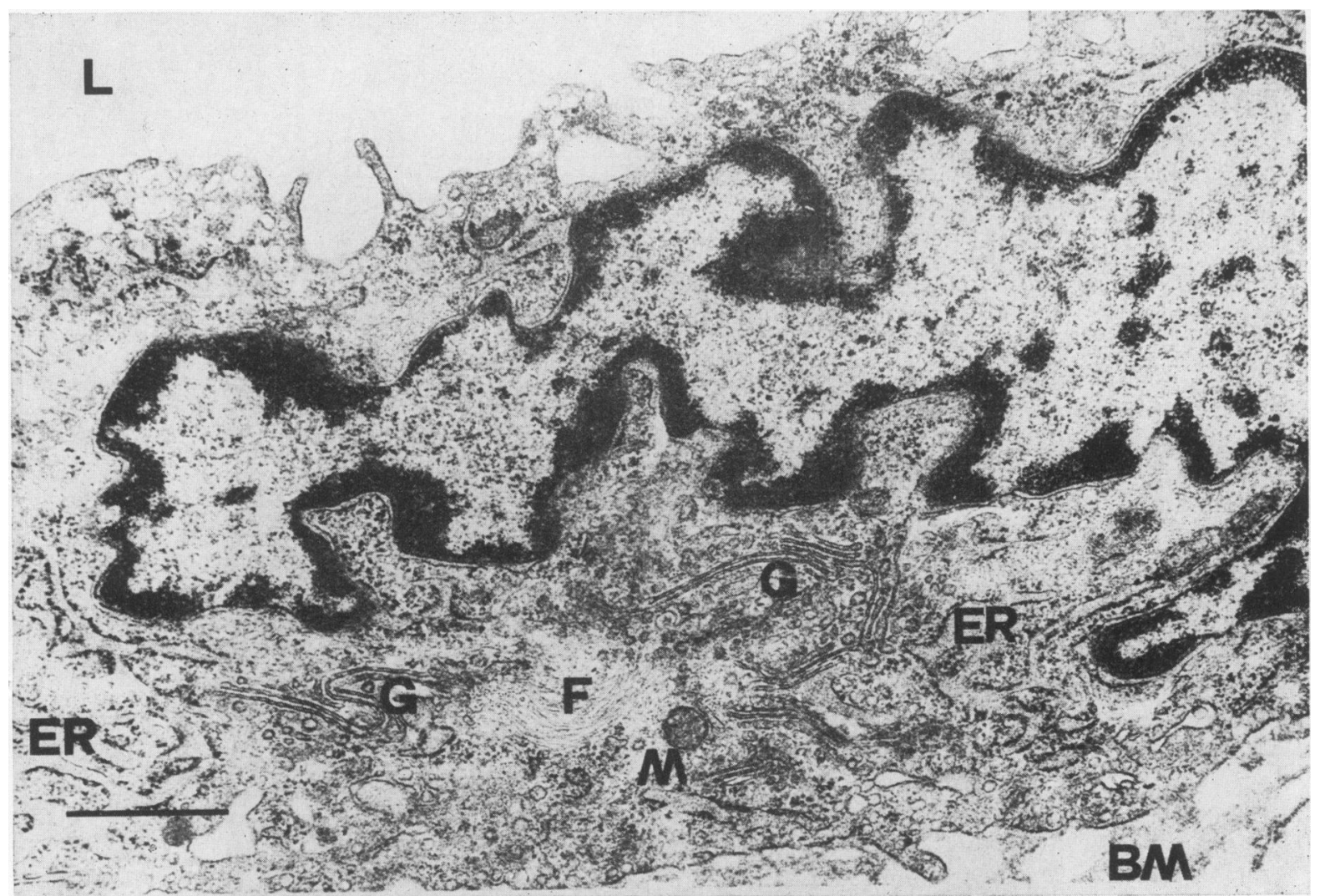

FIG. 2. Transmission electronmicrograph of an umbilical artery from a child of a non-smoking mother. Bar indicates $1 \mu \mathrm{m}$. $\mathbf{E R}=$ endoplasmic reticulum. $\mathbf{L}=$ lumen. $\mathbf{M}=$ mitochondria. $\mathbf{F}=$ filaments. $\mathbf{G}=\mathbf{G o l g i - a p p a r a t u s} . \mathbf{B M}=$ basement membrane.

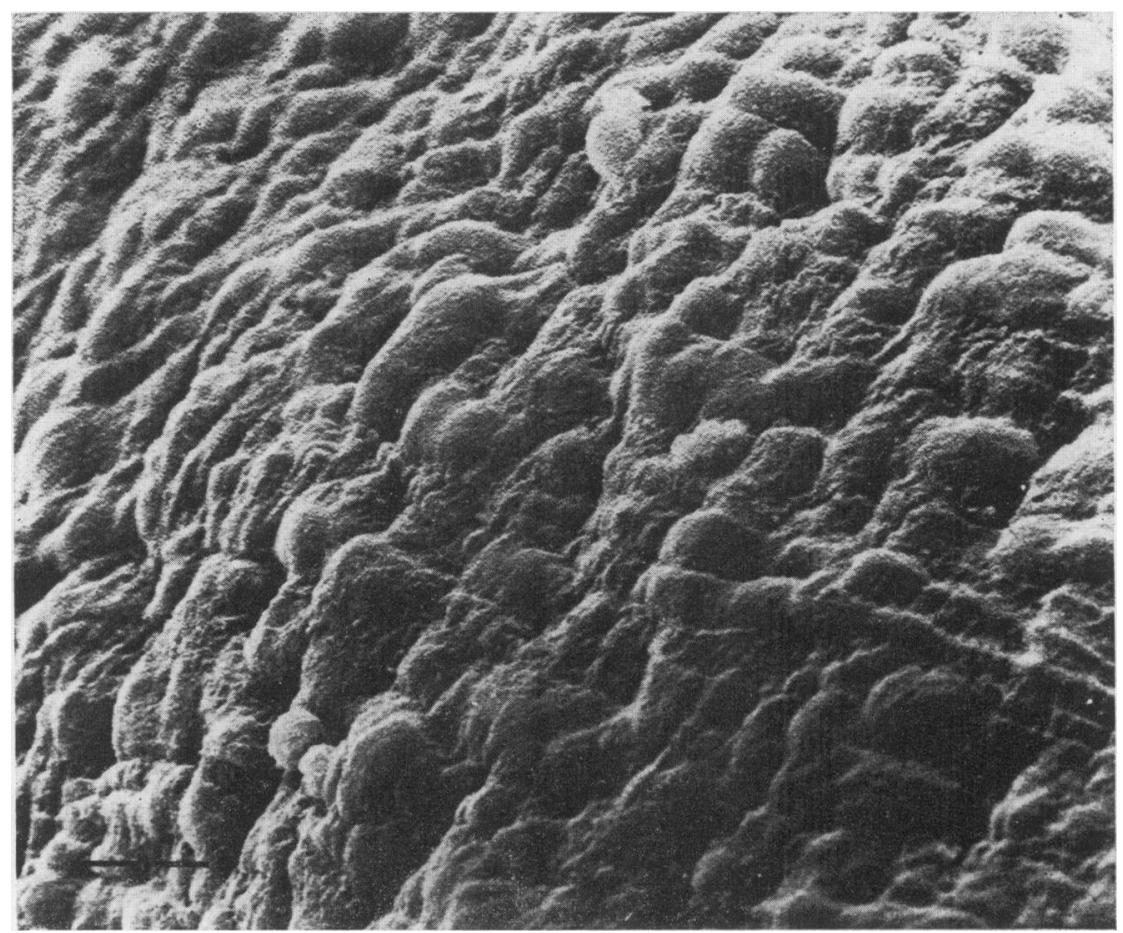

Fig. 3. Scanning electronmicrograph of the surface of an umbilical artery from a child of a smoking mother (20 cigarettes per day). Bar indicates $20 \mu \mathrm{m}$. 


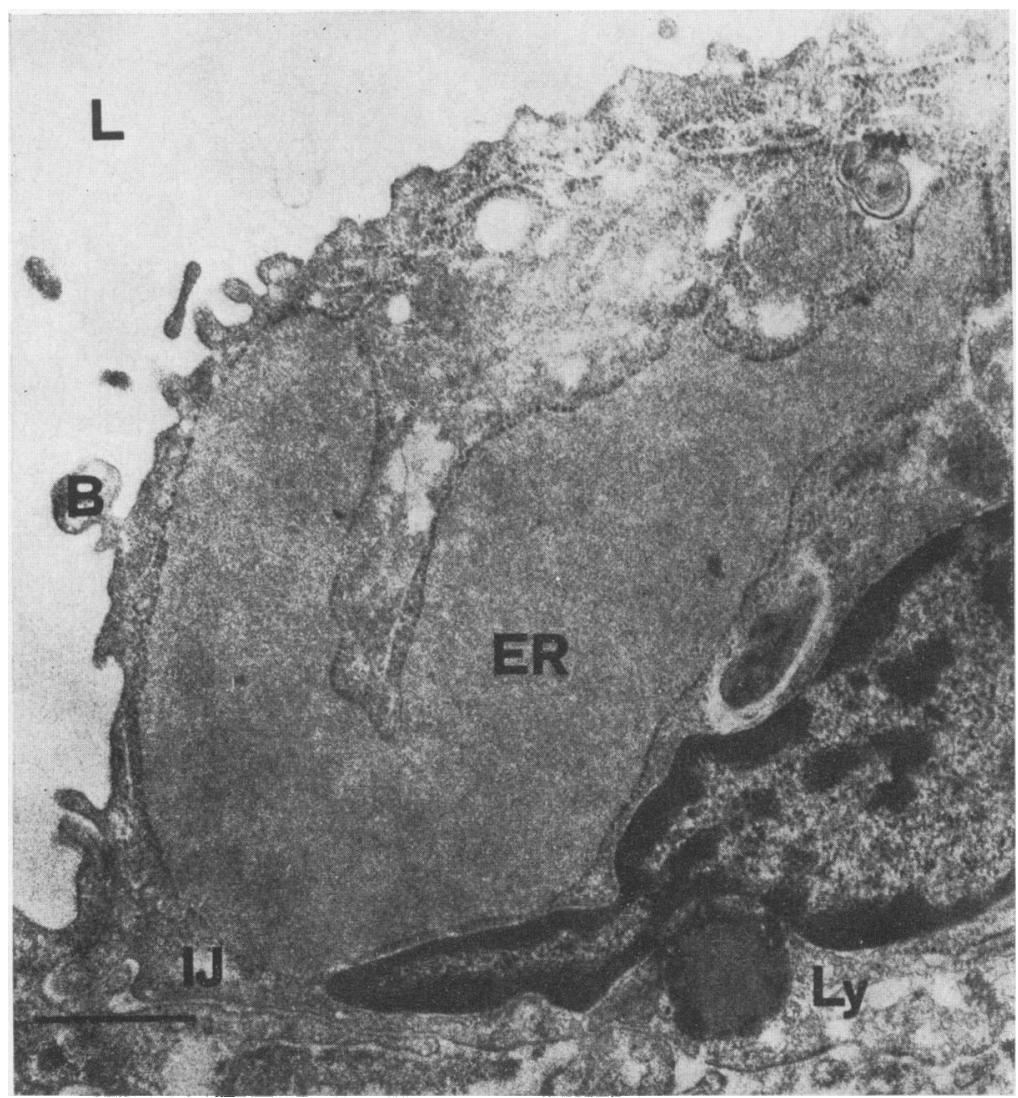

Fig. 4. Transmission electronmicrograph of an endothelial cell from an umbilical artery from a child of a smoking mother (60 cigarettes per day). Bar indicates $1 \mu \mathrm{m} . \mathrm{L}=$ lumen. $\mathbf{B}=$ bleb. $\mathbf{E R}=$ endoplasmic reticulum. $\mathbf{L Y}=$ lysosome. IJ = intercellular junction.

When compared with a control group of fifteen nonsmokers the biopsies revealed severe vascular damage (Asmussen, 1975, 1976, 1977a and b). Similar changes in vessels have been demonstrated in experimental animals using hypoxia, carbon monoxide, catecholamines, nicotine, etc.

A group of normal and healthy pregnant women were selected for the study. None had been treated with drugs. Blood and urine analyses and random tests of oestriol during pregnancy were normal. The women had normal pregnancies and deliveries and gave birth to healthy normal children at term. Subjects were divided into two groups. A group of heavy-smoking women were defined as those smoking and inhaling more than ten cigarettes daily both before and during pregnancy. One subject smoked 60 cigarettes daily. The control group consisted of non-smokers who had never smoked.

The birth weight of the children of the heavysmoking mothers was about $10 \%$ less than that of the controls (Asmussen and Kjeldsen, 1975). Theo mean placental weights of the smokers was about $20 \%$ less than that of the controls. A significant finding was that $80 \%$ of the children born to heavy smoking mothers were females compared with ao normal sex distribution among those born to non smokers.

Examination of the umbilical vessels was carried $>$ out by both scanning electronmicroscopy (SEM) and을. by transmission electronmicroscopy (TEM). Then specimens were examined without knowledge of the subjects' smoking habits.

SEM of the umbilical artery of a non-smoker N (Fig. 1) showed a normal smooth surface. Endo-O thelial cells followed a spiral course throughout the vessel and the endothelial cells were arranged in a regular pattern. TEM (Fig. 2) from a non-smoker? showed a closely attached endothelial lining, the cells attached to each other with closed intercellularo junctions. The endothelial cells were arranged on $a_{\Omega}^{\mathbb{D}}$ 


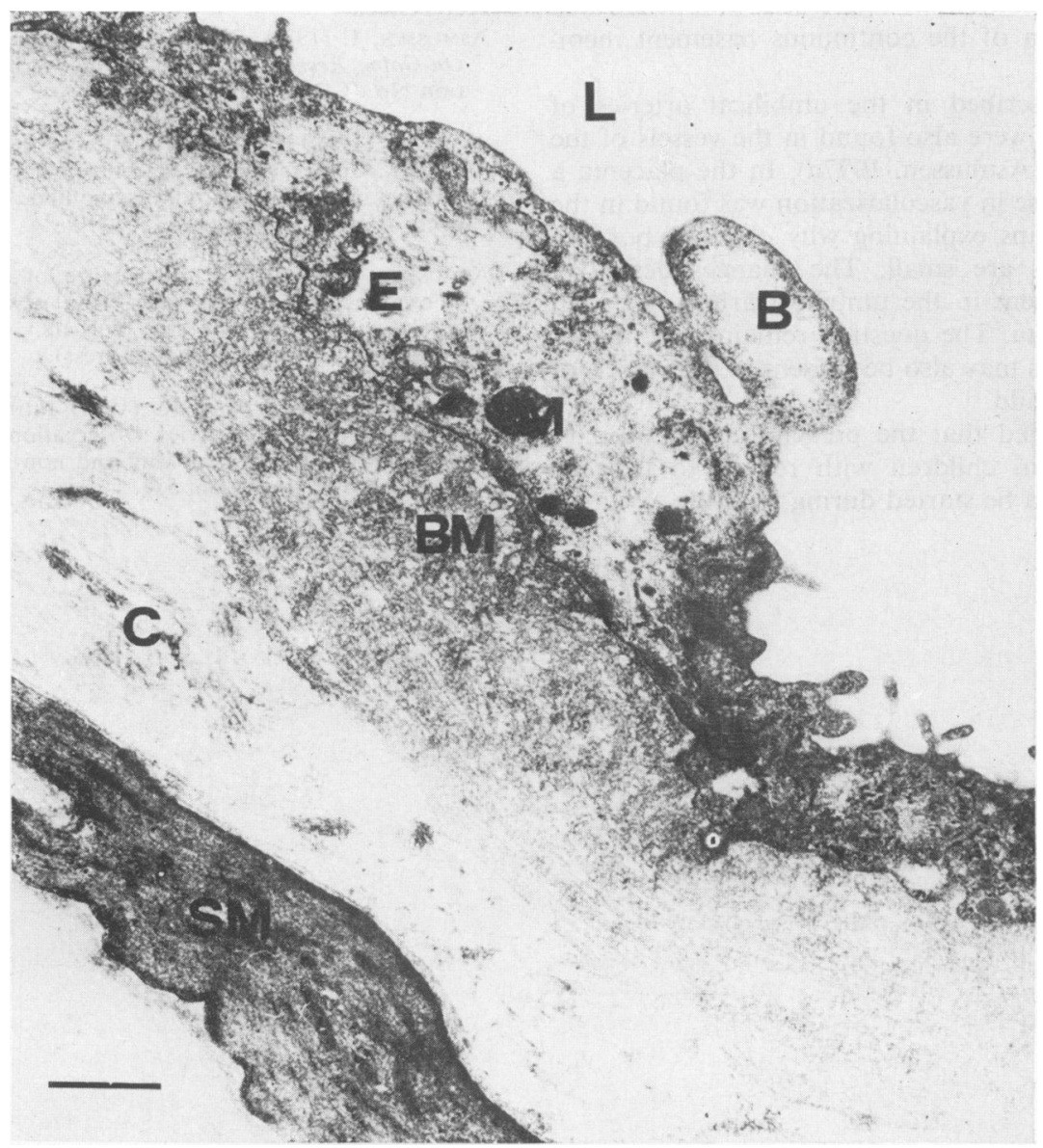

FIg. 5. Transmission electronmicrograph of the intima of an umbilical artery from a child of a smoking mother (25 cigarettes per day). Bar indicates $1 \mu \mathrm{m}$. $\mathrm{L}=$ lumen. $\mathbf{B}=$ bleb. $\mathbf{E}=$ endothelium. $\mathbf{M}=$ mitochondria. $\mathbf{B M}=$ basement membrane. $\mathbf{C}=$ collagen fibres. $\mathbf{S M}=$ smooth muscle cell.

non-continuous basement membrane of an approximate width of $0.1 \mu \mathrm{m}$. All the usual organelles were present in the endothelial cells, i.e. the Golgi apparatus, the mitochondria, the rough endoplasmic recticulum, the filaments, centrioles and the nucleus and nucleolus. The media myocytes were normal.

SEM (Fig. 3) from a healthy new-born child whose mother smoked 20 cigarettes daily, shows the lumenal surface of the umbilical artery. The most striking finding is the very irregular pattern found in the surface which shows a cobblestone appearance. In those mothers who smoked more than 20 cigarettes daily the pattern became even more irregular, the cells being studded with blebs on the lumenal surface.

Under TEM the endothelial cells showed dilatation of the rough endoplasmic reticulum (Fig. 4), a remarkable finding which might explain why the cells bulged into the lumen. On the surface are blebs which are thought to be due to intercellular oedema (Figs. 4 and 5). The wheel-like appearance of the lysosomes is also shown (Fig. 4). Fig. 5 shows a huge bleb on the lumenal surface of the endothelial cells.

A finding which was only present in the smokers was the extreme broadening of the basement membrane to about the same width as the endothelial lining. In the subject who smoked 60 cigarettes/day it was widened to about 35 times the normal. The broad basement membrane was continuous unlike that of the non-smokers who did not have continuous basement membranes. This might be due to an attempt at repair, although many of the other findings might be regarded as degenerative. Severe changes were also present in the media myocytes 
which became somewhat 'aggressive' and penetrated into the lamina of the continuous basement membrane.

Changes described in the umbilical arteries of heavy smokers were also found in the vessels of the placental villi (Asmussen, 1977a). In the placenta a marked decrease in vascularization was found in the smokers, perhaps explaining why children born to heavy smokers are small. The changes described above are present in the umbilical artery, the vein and the placenta. The question remains whether or not the changes may also be present in the vessels of the newborn child.

It is concluded that the prevention of coronary heart disease in children with regard to tobacco smoking should be started during fetal life.

\section{References}

ASMUSSEN, I. (1976) Smoking and Pregnancy. Directory of $\bigcirc$ On-Going Research in Smoking and Health. Hew publication No. (CDC) 8320, 086, 33.

ASMUSSEN, I. (1977a) Ultrastructure of the human placenta at term. Observations on placentas from newborn children of smoking and non-smoking mothers. Acta obstetrica et $\overline{\bar{\omega}}$ gynaecologica scandinavica, 56, 119.

ASMUSSEN, I. (1977b) Ultrastructure of human umbilical veins. Observations on veins from newborn children of ${ }^{\infty}$ smoking and non-smoking mothers. Acta obstetrica et $\vec{\circ}$ gynaecologica scandinavica (in press).

Asmussen, I. \& KJELDSEN, K. (1975) Intimal ultrastructure of human umbilical arteries. Observations on arteries from믐 newborn children of smoking and non-smoking mothers. Circulation Research, 36, 579. 